\title{
HIYA, FEMINILIDADE E GÊNERO
}

\section{Sandra Benato}

Recibido: 06/02/2018. Aceptado: 08/04/2018.

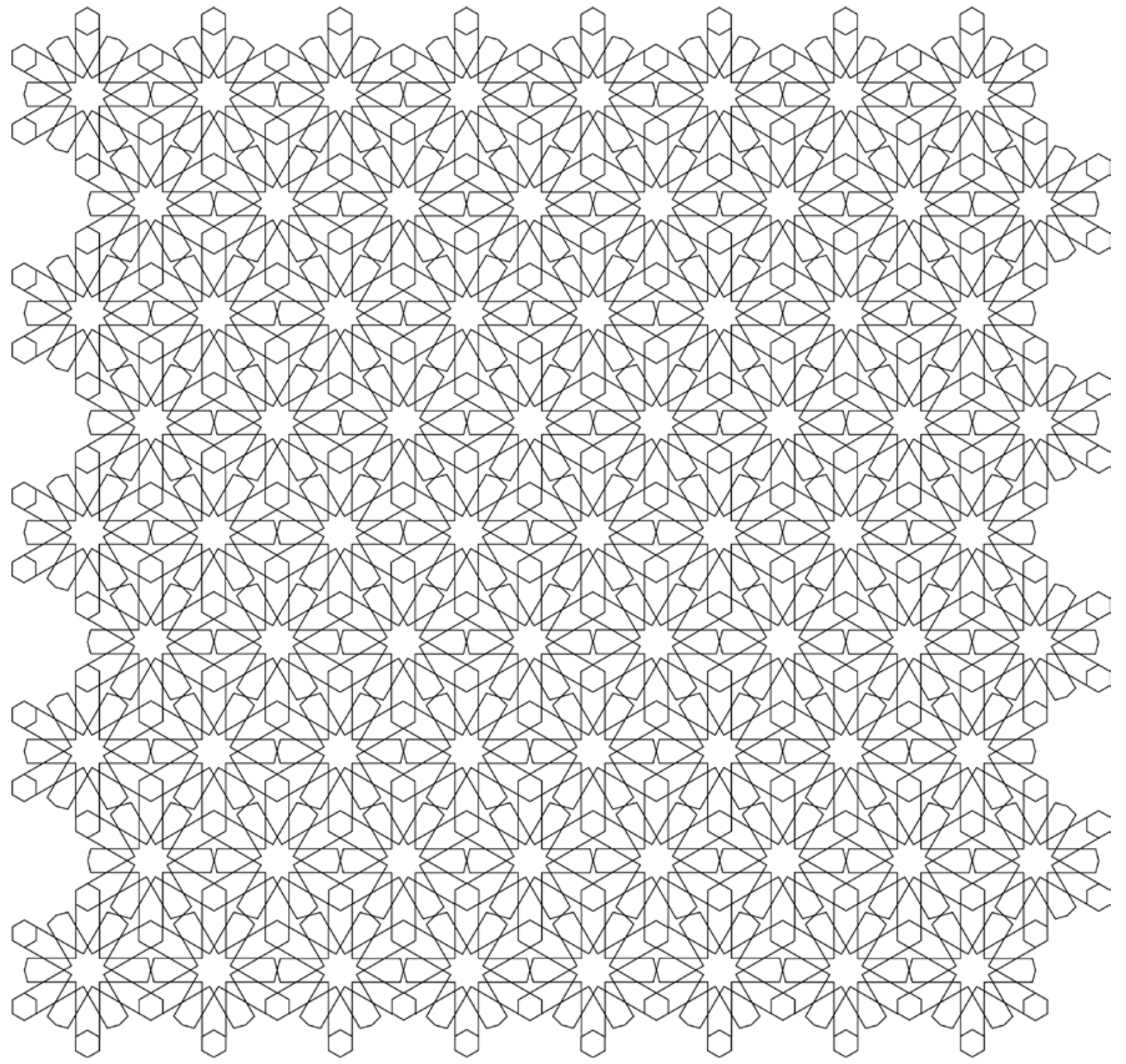


Resumo: Este artigo nasceu do "desassossego", como diria Fernando Pessoa. Aqueles que conhecem o trabalho de Ibn 'Arabī sabem da importância do feminino no seu pensamento e na consolidação das suas experiências espirituais. No entanto, ele também afirma que a mulher é segunda ao homem, surge de uma costela deste e lhe é inferior em um grau. Natural o desassossego, uma sensação de pinçamento cirúrgico e dolorido que não apenas inquieta a alma, mas penetra silenciosamente na sua carne mais profunda. Desfazer este nó intangível - mas opressor - é o que vamos tentar aqui, usando as próprias palavras do Šayh como fio condutor, a partir de seus vários conceitos associados à "triplicidade" como fundamento da vida.

Palavras chaves: Ibn 'Arabī, identidade essencial, feminilidade, triplicidade, gênero.

\begin{abstract}
This article springs out of a "disquietness", as Fernando Pessoa would say. Those who are familiar with Ibn 'Arabī's work know how important is the feminine in his thought as well in the consolidation of his spiritual experiences. However, he also states that the woman is second to man, rises from his rib and is one degree inferior to him. The "disquietness" so happen, naturally, as a sensation of a surgical and painful clamping that not only distresses the soul, but silently penetrates into its deepest flesh. To untie this intangible - but oppressive - knot, is what we will try here, by using the Sheikh's very words as a guiding thread, looking for the various forms where his concept of triplicity shows up as foundation of life.
\end{abstract}

Key words: Ibn 'Arabī, essential identity, femininity, triplicity, gender.

****

No Kitāb al-Huwa, o Livro da Ipseidade Divina, Ibn 'Arabī descreve, em termos de funções pronominais, o mesmo processo com que abre o Fusūs al-Hikam: a abertura de um espaço de consciência onde o Real quer contemplar ou conhecer Seus Mais Belos Nomes num objeto global que, dotado de vida, reflita a realidade, pois contemplar a si mesmo em outro não é o mesmo que contemplar a si mesmo em si mesmo. Este ato divino de auto-conhecimento segue o princípio de que ser e consciência, eu e eu-mesmo estão em relação de sinergia, como no sentido da palavra wuğūd, encontrar/ser-encontrado. Lembramos aqui o velho koan do monge Bassui: "quando pergunto por mim mesmo, quem é aquele que responde "eu"?"

Ibn 'Arabī responderia que se trata de um diálogo entre "ele" e a essência, ou seja, entre 
huwa - o pronome ausente e que despassa o sentido presencial de eu para se reportar a uma referência de si em si - e a essência, dāt, palavra gramaticalmente feminina que comporta a referência de hiya, ela (ela, minha "essência") ${ }^{1}$. Este diálogo se dá em termos de ato de si, expressão sinérgica da realidade de si mesmo, onde huwa e sua dāt estão necessariamente interceptados pelo alento do ser único que os descreve enquanto instâncias de si. O alento é $h \bar{a}$, o som mais internalizado das letras, simultaneamente a percepção mais profunda da consciência e o sopro vital que existencializa a vida. Escreve ele:

Quanto a quando huwa é hiya, isto não ocorre senão no confronto da existencialização de uma forma símile, pois huwa é um esposo e hiya, uma esposa, enquanto a $h \bar{a}$ 'é uma coisa que une huwa e hiya, como o termo médio que liga duas premissas que conduzem a uma conclusão, pois esse (o silogismo) é composto de três elementos. Portanto o termo médio é indispensável, já que huwa era e nada havia com ele. Huwa, enquanto huwa não possui wuğūd. Hiya, enquanto hiya, não possui wuğūd algum e com a $h \bar{a}$ ’ nāo há wuğūd algum. A ciência que se encontra na $y \bar{a}$ ' de $i n n \bar{\imath}$ precede a existencialização a fim de manifestar a verdade essencial dos Nomes: em função disso a $h \bar{a}$ ' move huwa e hiya. Huwa se encontra com hiya em $h \bar{a}^{\prime}$ e eis que ocorre a existência contingente ${ }^{2}$.

$\mathrm{O}$ ato de conhecimento é simultâneo ao de existência: o eu, ana, flexionado sobre si na posição da letra $y \bar{a}$ ' final de $i n n \bar{\imath}$, "em verdade eu", apresenta-se como o Vivo que se conhece a si mesmo, a consciência que se reflete a si mesma, wuǧŭd que encontra a si mesmo. Dito em outros termos, o transcendente, huwa, necessariamente encontra o imanente, hiya, ainda que este patamar signifique, em ambos, uma realidade metafísica transcendente. Retornamos ao mesmo tipo de correlação com a auto-referência pessoal em termos de realidade humana.

Como para Ibn 'Arabī o ser é único e sem divisões, na relação huwa/hiya não existem duas entidades, nem tão pouco uma hierarquia, apenas duas instâncias de si: huwa é hiya tanto quanto hiya é huwa. Isto nos leva a entender o transcendente não como uma realidade inconcebível ou sem existência, mas como uma realidade que depassa continuamente suas próprias formas, isto é, o processo de consciência de si que se reflete na existência de si remete-se continuamente a uma nova possibilidade de si mesmo e, deste modo, é independente dos mundos, pois a forma não o contém.

Quando o $\breve{S}$ ayh usa a expressão huwa se encontra com hiya em hā', usa o verbo iltaqa, que, traduz-

1 Note-se que Hiya também possui a mesma conotação de Huwa enquanto pronome ausente, transcendente.

2 Kitāb al-Huwa (Il Libro del Sé Divino), tradução de Chiara Casseler, p. 150 (Turim: Il Leone Verde, 2004). 
ido por "encontrar-se", significa achar-se face a face, frente a frente, ou ainda o "confluir das águas", como no confluir dos dois mares citado no Alcorão (55:19). Isto significa que huwa e hiya "confluem" um ao outro: o eu que quer se conhecer coloca-se frente a frente consigo mesmo e contempla as formas de seu próprio conhecimento que aparecem como imagens de si. Esta imaginalização ocasiona tağallī, o auto-desvelamento do Real, sinônimo de existencialização contingente: as criaturas só ocorrem como formas da realidade pela mútua contemplação ou pela confluência masculino/feminino, transcendente/imanente, no kun! o "sê!", o reconhecimento de si que vivifica.

Nesse encontro face a face há a presença de um terceiro, que simultaneamente é a força atrativa que mantém huwa e hiya como uma unicidade e o alento que intermedia a presença de huwa e de seu si mesmo, hiya. Note-se que o "imanente" só ocorre pelo "encontro" propiciado pela $h \bar{a}$ '. Ibn'Arabī usa vários termos para se referir a esta linha de demarcação, dependendo do plano de realidade a partir do qual esteja se referindo num determinado momento. Temos então o espaço da $h \bar{a}$, este "local" metafísico de toda realidade, com a denominação de "O Alento do Todo Misericordioso", "O Real-através-do-qual-a-criação-acontece"3, que acolhe as imagens da realidade como atos de wuğŭd ou auto-desvelamento do Real. Esta confluência de si a si ou este encontro necessário que implica no testemunho de si, innī "em verdade eu"- mostra huwa e hiya num mesmo plano de realidade onde encontrar e ser encontrado necessariamente reflete buscar e ser buscado: à medida em que as imagens de si se apresentam a partir de hiya, huwa as depassa, numa remissão infinita de possibilidades. Em outras palavras, o infinito em seu aspecto ativo e as possibilidades de si em seu aspecto passivo confluem no alento que se renova a cada instante ${ }^{4}$. No entanto, em si mesmos, não existem um "ativo" e um "passivo".

Hiya, a essência (o si mesmo), apresenta a huwa não apenas as formas que o caracterizam, suas potencialidades latentes, mas também a própria possibilidade de sua transcendência. Por outro lado, huwa, transcendendo-as, coloca-se "um grau acima", o "independente dos mundos", remetendo a própria hiya ao infinito. No entanto, este "grau acima" ou "além" é correlato ao próprio si mesmo caracterizado por hiya, pois a essência, a cada nova determinação ou imagem de si transcendida, apresenta uma nova possibilidade, de modo que "o Real necessariamente se encontra a si mesmo". Assim, o grau acima de um deve-se ao grau abaixo de outro, mas simultaneamente o grau abaixo de hiya conduz à transcendência pela apresentação de uma nova forma onde o Real se reconhece e se depassa. A correlação, como o alento da $h \bar{a}$, implica em reciprocidade e ambivalência, onde os dois polos são validados

3 Segundo a terminologia estabelecida a partir das traduções de William Chittick. De fato, Ibn 'Arabī usa vários termos, dependendo do ponto de vista que queira abordar. Seria muito extenso nos referirmos aqui a todos eles. 4 A renovação a cada instante é outro conceito que permeia o pensamento de Ibn 'Arabī. Segundo ele o Real nunca se apresenta o mesmo em dois instantes consecutivos, conforme o verso corânico "A cada dia Ele está ocupado em uma nova obra" (55:30). 
simultaneamente e onde ocorre uma identidade mutuamente transitiva. Aquilo que os une enquanto identidade é igualmente aquilo que os diferencia e aquilo que os diferencia é igualmente aquilo que os determina, de modo que o interior se traduz em exterior e o exterior se remete ao interior. Esta transitividade é o movimento da vida por ela mesma, inerente à traduzibilidade de sua haqq̃qa (realidade). Não há, nem mesmo na "relação" transcendência/ imanência, um grau hierárquico, mas de correlação: enquanto absolutos não possuem wuğūd. O Real é, portanto, a realidade integrada huwa/hiya, que Ibn 'Arabī chama de Presença Divina, al-ḥadra al-ilāhiyya, definida por Essência, Atributos e Atos, retornando novamente à noção de três como fundamento da existência ancorada na unicidade do ser.

"O segredo da existência é (universalmente) correlato", escreve o Šayh, sirr al-wuǧūd murtabit. Correlação implica tanto em mútua dependência quanto em mútuo depassamento: na medida em que o ser se apresenta, automaticamente se transcende e se renova. Se a reciprocidade traz uma consciência unitiva do Real, a própria tradução em uma forma se apresenta como um "outro", um terceiro que representa a transitividade da identidade, o passamento e depassamento entre um e outro, o "diálogo do si mesmo". Isto é tão intrinsicamente coeso que, como escreve Ibn 'Arabī, se algo se despregasse do fundamento da Realidade simplesmente não existiria.

Como um espaço de consciência, por um lado, e como um "casamento", por outro, a confluência huwa/hiya produz um "filho", um terceiro, simultaneamente uma realidade epistemológica e ontológica chamada al-insān al-kāmil, o ser humano perfeito (completo), forma receptiva a todos os nomes da realidade, o "ponto de visão" do Real, a 'ayn (a pupila) que se contempla a si mesma. A noção de ponto de visão também é a de espelho da realidade que acolhe os infinitos desvelamentos das formas da vida e que dá suporte ao sentido de identidade humana. As sucessivas formas do Real são singularmente acolhidas numa configuração específica, chamada 'ayn tābita, "identidade fixa", um espaço de receptividade vazio de si que porta um aspecto do Real. Este conceito responde pela multiplicidade das criaturas enquanto local dos atributos de wuğŭd, ou das qualidades da existência, e comportam aspectos da realidade, especificidades ou modos de ser/conhecer do Real. Enquanto modo de ser, seu aparecimento é o aparecimento do Real numa forma determinada. Enquanto modo de conhecimento, seu aparecimento testemunha a realidade sob um determinado ponto de vista.

\section{O HUMANO E SEUS CORPOS}


O objeto global no qual o Real se reflete, al-insān al-kāmil, acolhe não o sentido exclusivo de "homem", mas de "humano", no sentido universal de humanidade e aponta para o particular das criaturas, na multiplicidade das identidades do Real, como potencialmente completas pois, apesar de determinações específicas da realidade, referem-se ao mesmo nominado. A dinâmica transitiva de huwa/hiya repete-se aqui: o ser humano completo expressa os nomes da Realidade e está, portanto, para o Real, assim como o si mesmo está para o eu. Sob este ponto de vista, Ibn 'Arabī afirma que todas as criaturas, independentemente de gênero, são "fêmeas", pois são local da Presença do Real, atos da Essência, entificação de Seus atributos, em si mesmas únicas, mas igualmente depassadas pela multiplicidade das formas da realidade, de tal modo que cada criatura é vista como huwa/la-huwa, ele não-ele, afirmadas e negadas enquanto ipseidade.

No capítulo 7 do al-Futūhāt al-makkiyya, Ibn 'Arabī trata do aparecimento das formas visíveis no cosmos e das relações de tempo entre elas; a última forma é aquela que o Real elabora com "suas duas mãos": o corpo adâmico, a forma que recebe a plenitude de al-insān al-kāmil e, portanto, potencialmente receptiva a todos os nomes da Realidade. Este corpo, escreve o Šayh, foi chamado bašar, mortal, "e associou nele os opostos, com base num princípio de contiguidade e o configurou para um movimento ereto" ", e soprou nele Seu espírito. Se al-insān al-kāmil é o plano espiritual da plenitude da criação, Adão é a forma humana por excelência, à semelhança da forma divina, moldada pelo contato com as duas mãos divinas, isto é, os atributos da Beleza e da Majestade, dinâmicas correlatas que sintetizam os Nomes divinos. A partir deste corpo inclusivo, três outros surgem, de modo que os corpos humanos são de quatro tipos: o corpo de Adão, o corpo de Eva, o corpo de Jesus e aquele dos filhos de Adão.

Se considerarmos, por exemplo, os relatos do Šayh no Alquimia da Felicidade ${ }^{7}$, comparados aos do capítulo 367 das Futūhāt, onde Ibn 'Arabī trata da ascensão ou da viagem da alma e o Kitāb Inšă al-dawā'ir, podemos entender que para cada nível cósmico (os diversos planos do ser), há uma forma ou um corpo específico que abriga o sentido de identidade (eu sou). Podemos usar ainda a metáfora do véu: o ser, envolto por vários véus, desvela-se. Nos dois primeiros textos, onde Ibn 'Arabī relata suas próprias experiências de ascensão espiritual (ou de individuação plena), descreve como, em cada plano da ascensão, deixa para trás um corpo ou envoltório específico àquele plano. Esses quatro corpos característicos da forma humana correspondem a estes planos ou níveis de abrangência. Entre cada um deles, um istmo, um barzah que os separa e distingue e que dá acesso a "um grau a mais", um sentido progressivo de plenitude.

O corpo de Adão encontra referência corânica, por exemplo, em 7:189 - "Foi Ele quem vos

5 Veja-se, William Chittick, The Sufi Path of Knowledge, p. 385, nota 10, onde este explica que, em árabe, insān não possui conotação de gênero, ainda que seja uma palavra gramaticalmente masculina e ambos, homens e mulheres, são igualmente insān. O mesmo ocorre em português.

6 Eric Winkel, The Alphabet, p. 194.

7 A Alquimia da Felicidade Perfeita, tradução de Roberto Ahmad Cattani. São Paulo: Landi, 2002. 
criou de uma única alma/pessoa (nafs) e dela plasmou sua esposa, para que nela encontrasse segurança (ou equilibrio)"8. Como escreve Sachiko Murata, na gramática árabe, a palavra nafs é feminina, enquanto esposa, zawağ, é masculina e esta passagem cita Adão como uma "alma" ou pessoa única e o pronome para se referir a ela é feminino. No entanto, escreve Murata,

O pronome muda rapidamente de modo que Adão torna-se masculino e "esposa" feminino. Se fôssemos observar o uso gramatical do gênero, o verso 7:189 poderia ser traduzido por: 'Foi Ele quem o criou de uma única alma (Adão) e fez dela (da alma) sua esposa (Eva)'. De qualquer modo o verso se refere a como o yin surge de Adão, o andrógino primordial que contém tanto o masculino quanto o feminino. O jogo dos pronomes pode ser lido, ao estilo sufi, como uma 'alusão' (ǐšâra) divina: a presença do yin no yang e do yang no yin. ${ }^{9}$

Na sequência o relato mostra o aparecimento de um "filho". O versículo nos faz pensar que, ainda que o corpo adâmico seja não só único, mas uma unicidade, seu equilíbrio ou sua estabilidade depende da ambivalência (yin/yang, feminino-masculino). Por um lado, a forma adâmica reflete o sentido de "causa" como co-extensivo a "efeito" pois são correlatos e, em si mesmos, "infirmes"10, onde a causa é efeito de seu próprio efeito, o que implica na traduzibilidade dos correlatos. Por outro, esta mesma traduzibilidade mostra-se como triplicidade, a força atrativa da paridade ou a confluência capaz de geração tanto de sentido quanto de forma.

Assim, o corpo de Eva é a primeira diferenciação do corpo adâmico, esculpido a partir de uma costela desse: "Nada faz de uma coisa duas senão ela própria, seja no nível sensorial ou inteligível. Quanto ao nível sensorial, Adão tornou-se dois por aquilo que se abriu a partir de sua costela esquerda, isto é, a forma de Eva. Ele era um em sua entidade e tornou-se par através dela, ainda que ela não seja senão ele mesmo"11.

Segundo Fabre d'Olivet, em La Langue Hébraïque Restituée, o termo costela significa "aquilo que se liga à toda inflexão, à toda forma circunferencial, à toda superfície exterior das coisas... Portanto, a palavra significa exatamente um envoltório, um véu exterior, um abrigo

8 Le Coran, tradução de Régis Blachère, p. 199. A palavra "segurança" pode ser entendida tanto com o equilíbrio quanto estabilidade, coerência, junção.

9 Sachiko Murata, The Tao of Islam: Gender Relationship in Islamic Thought, p. 342, nota 10.

10 Veja-se Chittick, The Self-Disclosure of God, p. 18: "O termo 'illa em árabe significa não somente 'causa', mas também 'infirmidade', assim como ma'lül, significa não somente 'coisa causada' ou 'efeito', mas também 'infirme' ". Infirme, com a conotação de não-estável, enfermo. Ou ainda: al-'illa ma qüla li-mā hiya ílla la-hu - a causa é efeito daquilo de que é causa - um princípio de reciprocidade na correlação que implica na lógica do terceiro incluído.

11 Futūhät III, 314.22: Sufi Path of Knowledge, pp. 358-359. 
protetor..., um ser que envolve, cobre, envelopa". Essa forma foi denominada "mulher" ou "esposa" e, escreve Ibn 'Arabī, "apareceu segundo a forma do homem e este sentiu por ela uma atração viva que uma coisa sente por si mesma; de sua parte ela sente por ele a atração que alguém sente por seu país natal”.

Eva é, então, o próprio aspecto de "identidade" do espirito adâmico enquanto "ligação": a costela que polariza o espirito em suas potencialidades, que se curva em direção ao coração para protegê-lo, sua habilidade imaginal (no sentido de formação de imagens), de recepção das realidades inerentes ao espirito, da abertura para as possibilidades da forma. $\mathrm{O}$ corpo de Eva sofre a flutuação e a ambiguidade das possibilidades da consciência, de opção entre o Real e o mundo, eu/não-eu. Enquanto princípio, já estava no espírito, no corpo adâmico, a partir do qual possibilita a atualização de 'ayn tābita, a ligação entre o universal e o pessoal, entre o interior e o exterior. Estende-se entre a forma imaginal individual ou polo psico-físico e as luzes dos significados da presença dos Nomes da Identidade: entre o corpo físico e o espiritual.

Assim, Eva, a Alma, corresponde ao aspecto que movimenta a consciência do ser, que aciona a polaridade inerente a wuğŭd enquanto ser consciente de si, seu vir-a-ser, que lhe abre as portas de sua constituição e replica a correlação Huwa-Hiya de formação e depassamento das imagens. Neste sentido, o plano do corpo de Eva é o mundus imaginalis, o intermediário entre o plano espiritual e o físico e simboliza a polarização da reprodução sexuada das imagens, a confluência de dois mundos: é o plano onde o espírito se corporaliza e o corpo se espiritualiza. Do mundo físico recebe as impressões em forma imaginal e do espírito, os significados, através dos Nomes atuantes em 'ayn tābita. Note-se, portanto, que os Atributos divinos, dos quais os Nomes são referência - e que se desvelam na Identidade essencial que constitui toda criatura - são realidades simultaneamente ontológicas e epistemológicas: originam tanto a entificação quanto a consciência ou um modo de conhecimento específico a cada existente.

Enquanto o corpo adâmico é o envoltório que abriga a Identidade essencial, o corpo de Eva o vincula ao mundo dos elementos orgânicos. Assim, ela é uma "esposa" que, na época de Ibn 'Arabī, tinha a conotação de um "campo a ser arado e semeado". O papel feminino nas sociedades tradicionais (e, em grande parte, até mesmo na atualidade) é associado puramente à sua expressão biológica, sem que a mulher possua em si nenhum sentido de "pessoa": ela é o sustento para seus filhos e o prazer para seu marido. Como escreve Su'ād Hakīm, no contexto tradicional islâmico, a mulher "completa" é aquela que:

Dedica-se a cuidar de seus filhos, a esposa virtuosa que conduz o lar, amante, paciente e agradecida... É a mãe, a filha a irmã e a esposa... sem entidade por si mesma. Seu ser é determinado por suas funções, suas relações familiares e seu único caminho, além da reclusão familiar, aparece em suas relações com seu Criador e seu 
Adorado... Aqui também se encontram muitas regras e restrições que a impulsionam a levar sua relação com Deus de de modo isolado, longe das multidões e das sociedades. ${ }^{12}$

No texto do $\breve{S} a y h$, ambas as conotações, espiritual e social - a do corpo de Eva enquanto sinal exterior de gênero e enquanto alma - estão presentes. Lembremos que Ibn 'Arabi também é um "zăhirista", um "literalista". Seria muito extenso tratar desta questão aqui, mas, de modo geral podemos afirmar que segue a orientação corânica de que tudo é um "sinal" da Presença divina e a literalidade deste sinal aponta para a qualidade ou o grau dessa Presença e seus processos criativos. Para o Šayh̆, tudo, inclusive os seres humanos, são sinais ou imagens que devem ser remetidos à Presença do Real. Essa remissão segue o sentido do "rasgar os véus", do desvelamento ou do atravessamento da forma: é "através" do sinal que se abrem seus significados ou suas realidades.

A seguir temos o corpo de Jesus que, segundo a descrição do relato corânico, foi criado a partir do corpo de Maria e do Alento divino intermediado pelo anjo Gabriel. Quando Ibn "Arabī discute este corpo, avança sobre o conhecimento "científico" de sua época: o princípio ativo da geração era associado unicamente ao sêmen masculino, enquanto a mulher era considerada apenas como o receptáculo uterino, a exemplo da terra a ser semeada e, portanto, sem participação alguma na "semente" constitutiva do feto. Ibn 'Arabī escreve: "Os sábios naturalistas negam que algo possa ser criado a partir dos fluidos da mulher, mas isso não é correto. Para nós, o ser humano é criado a partir dos fluidos do homem e da mulher"13.

O corpo de Jesus, se considerado a partir do entendimento de Eva como o corpo da alma, corresponderia ao plano do coração, tão fundamental para o pensamento de Ibn'Arabī, a Caaba singular que abriga a Presença divina em cada ser. Nele, as imagens da alma, tanto quanto o corpo feminino de Maria que lhe serviu de "mãe", portam os sinais do mundo; o alento da Presença, através do sopro de Gabriel, lhe confere sua qualidade "crística": o coração torna-se então o portador do "trono" divino, capaz de assumir todas as formas, o ponto de "unificação" (ittiḥ̂ad) e transitividade da realidade.

O quarto tipo de corpo humano é aquele dos filhos de Adão, o organismo gerado pela reprodução sexuada. Este último corpo recebe o sentido de gênero orientado pela confluência dos correlatos ou seja, pela receptividade de sua matéria orgânica enquanto expressão viva da Identidade essencial e em correspondência com essa. Isto significa que aquilo que orienta a masculinidade ou a feminilidade é a mesma disposição principial de huwa/hiya, a traduzibilidade dos nomes do Real.

\section{GÊNERO, GRAU, PLENITUDE: GORAÇÃO GOMO TRANSITIVIDADE}

12 Su'ād Hakīm, "Santidad y feminidad en la vida y obra de Ibn Arab $\vec{\imath}$, Mujeres de Luz, p. 188 (edição de Pablo Beneito). 13 Futūhāt, capítulo 298 (7:329): The Alphabet, p. 204. 
Assim como o corpo adâmico, constituído entre as duas mãos divinas, consideradas a partir dos Nomes da Majestade e da Beleza, a Identidade essencial de cada criatura configura-se conforme o auto-conhecimento que wuğūd encontre em si e que se traduz na receptividade da criatura, vazia de ser, em assumir esta realidade. Podemos entender, portanto, que a determinação essencial das entidades depende da predominância dos nomes do Real: se, na relação encontrar-ser-encontrado de wuğūd que se transfere ao vazio de 'ayn tābita predominarem os nomes da Majestade, a masculinidade prepondera; se predominarem os nomes da Beleza, o feminino acontece.

Por um outro lado, se a Identidade essencial pode ser considerada como "fixa" - sendo fixo um dos sentidos de tābita - um modo determinado de auto-conhecimento do Real, cada criatura possui uma configuração específica ou uma predisposição (uma rosa é uma rosa, um tomate é um tomate, uma pedra é uma pedra, etc). Por outro lado, esta configuração específica nunca é absolutamente masculina nem absolutamente feminina, pois um absoluto nunca se expressa numa forma definitiva ${ }^{14}$. Como escreve Ibn 'Arabī, "De fato, nada há de absoluto: os possíveis não o impõem nem as realidades o provêm, pois o absoluto é uma determinação. Coisa alguma ocorre senão num contexto que a aceita ou num contexto que a repele. Inexoravelmente é assim"15. Os Nomes se desvelam conforme os locais que os recebem. Isto implica que cada criatura é entificada, de acordo com sua predisposição, a partir de uma associação de atributos do ser, ou uma associação de aspectos essenciais que, a exemplo do objeto global de Adão, traduzem a potencialidade de al-insān al-kāmil - um ser humano capaz de expressão da Realidade.

"Atingir a perfeição $(k a m a \bar{l})$ não é um impedimento para as mulheres, ainda que elas possuam um grau a menos que os homens", escreve o Šayh. Este "grau" refere-se à feminilidade como local de manifestação do Real, o local da receptividade e da passividade, da geração e da exteriorização e, nesse sentido, todo visível é "feminino", de tal modo que Ibn "Arabī afirma que qualquer local que não aceite o feminino é inócuo, inoperante. Feminilidade, portanto, não pode ser compreendida em termos de gênero, pois o gênero depende do Atributo divino que o engendra e, como todos os atributos pertencem ao Real, todos se referem ao mesmo nominado e "não há nada deficiente no universo pois do completo nada se origina senão aquilo que é comensurável com a compleição que Lhe é adequada"16. Assim o "grau" implica na abrangência da traduzibilidade do Real, isto é, o espírito adâmico, tanto em homens quanto em mulheres, está mais "próximo" da realidade essencial do que o corpo de Eva (enquanto alma), pois o corpo de Eva contém imagens que derivam tanto de Adão quanto do mundo material, passível de "corrupção", de decaimento e depassamento da imagem.

14 Como na citação: "Huwa era e nada havia com ele. Huwa, enquanto Huwa não possui wuğũd. Hiya, enquanto Hiya, não possui wuğ̌ud algum “.

15 Futūhāt, capitulo 71: Eric Winkel, Mysteries of the Fast, p. 226.

16 Futūhāt, capitulo 72: Eric Winkel, Mysteries of the Pilgrimage, p. 60. 
No entanto, Ibn 'Arabī não deixa de afirmar que a qualidade mineral é uma das qualidades mais elevadas pois "as pedras são criaturas puras que nunca deixam sua raiz nem sua configuração... ao contrário do ser humano, cujo coração oscila em função de se presumir divino" ${ }^{17}$. Enquanto o mineral permanece puro em sua manifestação, o ser humano pode "enferrujar" seu coração, voltar-se apenas para uma face da realidade, encher-se da presunção dos absolutos. A perfeição exige o polimento do coração, a abertura para a transitividade entre a Presença essencial e sua manifestação no mundo: um coração cuja presença se delimita por uma consciência de ego (eu-bašărĭ, mortal) adere a um absoluto. Um coração transitivo abre-se à potência criativa da vida.

Exatamente esta centralidade do coração e sua habilidade de acolher todas as formas fazem dele o local da triplicidade, o processo de transitividade que intercepta consciência e vida. Por um lado, o Real está mais perto da criatura do que sua veia jugular - é no coração que os Nomes do Real, a presença da Identidade essencial, o "sopro" divino se desvela. Por outro, a veia jugular é exatamente a "corda" que unifica a vida essencial e a vida do alento no mundo. Novamente vemos aqui o Real como sincronização entre vida e consciência e é esta mesma sincronização que resulta numa "entidade" marcada pelo signo ou pelo sinal da "identidade". A triplicidade é, portanto, a tradução do Real em Realidade e, de modo criativo, a tríplice gradação ontológica da manifestação. Segundo Ibn 'Arabī, o processo também pode ser descrito em termos de luz, fogo e argila: mundo espiritual, mundo intermediário e mundo físico. Ainda que estes sejam necessariamente unificados enquanto expressão do ser ou de sua realidade, há entre eles um "grau" diferenciado, necessário para permitir a multiplicidade das formas, em si mesmas gradações pois, o invisível só produz efeito na medida em que se torne visível ou adquira uma forma.

De acordo com o $\breve{S} a y h$, o ato de ser, inerente ao Real, permeia o visível através de suas Identidades ou, de modo mais sucinto, através da Presença de Seus Nomes no mundo. Isto nos remete à luz e suas inúmeras potencialidades diferenciadas conforme o atributo do Nome que se faça presente. Em linguagem contemporânea, poderíamos comparar cada nome a um "elemento" constitutivo e qualitativo da realidade que, de fato, é tríplice, diversificada pela potência criativa de suas possibilidades de informação (ou consciência). Ibn 'Arabī afirma que cada um deles possui três níveis de configuração, que vão coincidir com os três planos básicos da existência: "A razão disso é que as luzes dos corpos celestiais se expandem até se conectarem aos sítios elementais e isso é o descenso das radiações e os elementos são capazes de aceitar em si o processo criativo" ${ }^{\prime 8}$. O espaço aberto pelo auto-conhecimento do Real que desvela as imagens produzidas por essa consciência transmite-se em termos de luz, ativa e receptiva e, entre estes dois aspectos, um terceiro, que se expressa como uma força atrativa ${ }^{19}$.

17 Idem p. 166.

18 Futūhăt, capítulo 72: Mysteries of Pilgrimage, p. 240. A triplicidade aqui aparece como Essência, Atributos e Atos. 19 Muito extenso para tratar deste tópico em detalhes. Veja-se Sufi Path of Knowledge, p. 212, para uma aborda- 
Isto nos indica que até mesmo a luz, para o $\breve{S} a y h$, ocorre como triplicidade.

Hoje a ciência nos informa que a luz, energia radiante, comporta-se simultaneamente como partícula e como onda e este comportamento gera campos magnéticos que dependem das fases da luz. "A fase da luz é a medida de um ponto específico no ciclo de uma onda de luz,

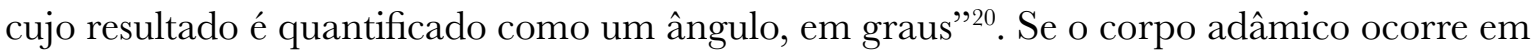
termos de luz, o corpo de Eva implica na diferenciação ou na polarização da luz através da "curvatura" da costela, de seu envelopamento amoroso do coração. Sabe-se que a luz se curva na medida em que é atraída por um campo magnético onde as funções da luz (como onda e partícula) entram em colapso. Nas palavras do Šayh:

Quanto a nós, não defendemos o argumento do centro atômico mas, ao contrário, defendemos um domínio para os essenciais. Argumentamos que o maior atrai o menor. E é por isso que vemos o vapor e o fogo buscarem elevação, enquanto a pedra busca o que está abaixo. As facetas diferem e esta é a ordem correta dos pares; isto é, um buscando o superior e o outro, o inferior. ${ }^{21}$

Podemos ver aí a relação entre os "graus" como um princípio de atração que unifica tanto as realidades da consciência (ou do inteligível) quanto da formação dos corpos - o encontro de wuğŭd consigo mesmo - um processo de correlação que permeia todos os planos do ser e que faz da triplicidade - o movimento atrativo - um processo de singularidade e vida ${ }^{22}$.

Assim, se considerarmos a polaridade adão/eva tanto em sua função metafísica de interioridade quanto na constituição orgânica do gênero característica dos organismos dos "filhos de Adão", podemos estabelecer a mesma relação de presença/consciência que permeia toda a realidade, isto é, entre eles há analogia e reciprocidade. Nos diversos "graus" ou planos do ser - vistos segundo a trajetória da luz como elemento vivificador - a mesma analogia e reciprocidade se repetem de acordo com a necessidade inerente àquele plano ou grau (seja no plano espiritual, no intermediário ou no físico).

\section{PARIDADE DOS PARES: AMBIVALÊNGIA E REGIPROGIDADE}

A correlação dos opostos a partir da analogia entre esses relaciona os princípios da atividade

gem direta, e Kitāb Inšă’ ad-daw⿳亠口冖̆ ir para um estudo em profundidade.

20 Veja-se "Non-reciprocal Phase Shift Induced by an Effective Magnetic Flux for Light", de Lawrence D. Tzuang, Kejie Fang, Paulo Nussenzveig, Shanhui Fan, Michal Lipson. Em NATURE PHOTONICS, Vol. 8, pp. 701-705.

21 The Alphabet, p. 257.

22 Veja-se Futūhāt, capítulo 20, 6:428 ou The Alphabet, p. 287. Veja-se também Futūhāt III, 276.1 onde Ibn 'Arabi escreve sobre o corpo a partir da triplicidade: do ponto à linha e da linha ao plano, e das dimensões altura, largura e profundidade. 
e da passividade - considerados, a princípio, como característicos do masculino e do feminino, respectivamente - num mesmo plano de relação, do mesmo modo que o corpo masculino de Adão surge simultaneamente ao corpo feminino de Eva, pois somente pela diferenciação do ser humano como realidade inclusiva podemos falar em gênero. Se a constituição de Adão, considerado a partir do ser humano completo, abriga todos os nomes do Real, sua polarização faz dele a "terra" do corpo físico onde aparecem os gêneros homem e mulher, sem que nenhum desses deixe de apresentar, em si mesmo, a unicidade original de Adão: o homem, em si mesmo, é masculino e feminino na medida em que possui uma "eva", uma alma, e que sua Identidade essencial é composta de nomes tanto da Majestade quanto da Beleza. Note-se que em cada nome há igualmente uma polarização: cada um deles tanto implica em uma ontologia quanto num modo de conhecimento ou consciência ${ }^{23}$. Portanto, não podemos associar somente o masculino ao intelecto, relegando o feminino à simples função laboral de parto e submissão à consciência enquanto atributo masculino, o que equivaleria a dizer que a mulher é uma forma bonita, prazeirosa, mas inconsciente pois isto significaria que ela não possui uma "alma".

Por outro lado, a mulher em si mesma, não existiria sem o princípio adâmico que nela responde como o envoltório que abriga o Senhor, o núcleo de sua Identidade essencial correspondente à presença do Real segundo Sua própria forma. Assim, ela não é apenas receptiva ou passiva, como se os nomes da Beleza, nela predominantes, fossem somente passivos. Cada elemento do par de correlatos já é em si mesmo uma unicidade da mesma polaridade que o constitui. Como escreve Ibn 'Arabī:

Quando duas preciosidades (ğawharān) são unidas, é como se fossem dois corpos. Isto porque cada um deles, unido ao outro, pode ser chamado um corpo (ğism) e, deste modo, são dois corpos, conforme Ele disse: 'de cada coisa, criamos dois pares' (A. 51:49). De fato Ele criou um par, masculino e feminino. Mas Ele os chamou 'dois pares', pois cada um deles, por si, sem o outro, não é um par, mas quando outro lhe é adicionado, cada um deles pode ser chamado um par (zawğ); então são dois pares ${ }^{24}$.

Em outras palavras, em cada um dos elementos do par já ocorre uma paridade, exatamente o que permite o relacionamento em correlação, pois ambos aceitam-se reciprocamente.

23 Ibn 'Arabī compara esta polarização com o trabalho do carpinteiro, que conhece seu ofício, sabe executá-lo e a madeira que recebe a forma de um armário, mesa, etc. Veja-se The Alphabet, p. 256. O que ocorre, escreve ele, é uma transferência de significados, um conhecimento e uma produção, consciência e vida, ambos inerentes a wuğùd.

24 Futūhāt, I, 721.18 - em Mohamed Haj Yousef, Ibn Arabī, Time and Cosmology, p. 205. 
No sufismo clássico, há a tendência a associar os nomes da transcendência aos atributos que causam um distanciamento da imanência: nomes com uma conotação mais dinâmica, impassível, absoluta, característicos do "pai", enquanto aos nomes da imanência associam-se virtudes como doçura, gentileza, amorosidade, característicos da "mãe", a que é submissa, passiva. Ora, quem quer que tenha experimentado o "poder da Doçura" sabe o quanto este nome pode ser ativo e mover a dinâmica da vida tanto quanto podemos observar no nome O Justo. Portanto, não é a masculinidade que é ativa, nem a feminilidade que é passiva, mas o local do acolhimento das funções masculinas ou femininas que são passivos em relação ao Real que neles se desvela, pois todos os nomes do Real são atos de si. Deste modo, tanto homens quanto mulheres são passivos diante do ser. Conforme escreve Chittick:

Apesar da Natureza ser vista primariamente como receptiva, ambas, a atividade (fā́iliyya) e a receptividade (qābiliyya) - ou a qualidade de estar sujeita à ação, infíăliyya - são manifestas através dela, pois o princípio superior que atua sobre a Natureza possui tanto a dimensão ativa quanto passiva. Em outras palavras, apesar da Natureza ser receptiva àquilo que lhe instila formas, as formas nela instiladas podem ser ativas ou receptivas, masculinas ou femininas, yang ou yin. No entanto, Ibn 'Arabī algumas vezes muda o ponto de vista a partir do qual se refere à Natureza e a vê como um princípio ativo ao invés de receptivo ${ }^{26}$.

O centro da questão é o espaço a partir do qual nos colocamos face a face à Identidade essencial, que reproduz o encontro de wuǧūd no reconhecimento de si mesmo e que faz o "atravessamento" ou a transferência do sentido. Para o $\breve{S}$ ayh, não se trata de "interpretar", mas de cruzar, ir através de, como ao atravessar um vale ou um riacho. Enquanto a interpretação conduz a uma outra metáfora, muitas vezes distinta do que a imagem propõe, o atravessamento conduz ao outro lado, ao significado por um desvelamento:

Relatar (ihblär) eventos chama-se "expressão" ( 'ibāra) e interpretar sonhos chama-se $t a$ 'bir, "interpretação". Isso porque aquele que reporta e aquele que interpreta "atravessam" ( $u b \bar{u} r$ ) através do que dizem. Por meio das palavras ele passa (jawāz) da presença (hadra) de si mesmo para a presença do ouvinte. Então suas palavras se transferem de imaginação a imaginação, pois o ouvinte imagina na medida de seu entendimento. A imaginação do locutor pode ou não coincidir com a imaginação do ouvinte. Se coincidirem, a isso chama-se "entendimento" (fahm); se não, ele não entendeu... e isto é uma alusão à 
imensidão do plano imaginal, o regente absoluto (al-hăkim al-mutlaq) sobre as coisas conhecidas. ${ }^{27}$

O mesmo processo que fundamenta a produção de imagens tanto produz o pensamento racional quanto a linguagem da mente durante o sono: relatar um fato ou um sonho são transferências de conteúdos de uma margem à outra, do espaço imaginal do locutor ao espaço imaginal do ouvinte. Isso significa que a transferência de imagens ocorre de acordo com o "influxo" dos nomes da Identidade essencial - tanto de locutor quanto de ouvinte - que se apresentem num dado momento e, portanto, as imagens não possuem um sentido pré-delimitado, mas dependem da "paridade" dos dois lados que se encontram no atravessamento ele mesmo. Este processo também justifica as palavras do $\breve{S} a y h$ :

A mulher em relação ao homem é como a Natureza em relação ao Comando Divino (al-amr al-ilāh $\vec{\imath}$, pois a mulher é o local da existência das entidades dos filhos, assim como a Natureza em relação ao Comando Divino é o local da manifestação das entidades dos corpos físicos. Através dela eles são engendrados e nela tornam-se manifestos. Deste modo, não pode haver um Comando sem Natureza e Natureza sem Comando e a existência depende de ambos. ${ }^{28}$

Portanto, a associação da mulher com a passividade carrega a noção cultural errônea de que passividade significa fragilidade, inércia, falta de iniciativa, submissão, uma "tabula rasa" que é marcada pela intenção de um absoluto masculino. Estas noções são antes fruto da percepção histórica-cultural vigente nas sociedades patriarcais, além de resultantes igualmente da ignorância sobre o corpo feminino, seus ciclos lunares de criação e destruição, seu ritmo de alternância entre luz e sombra ${ }^{29}$. Como afirma Ibn 'Arabī, o Real só concede realidade àquilo que é necessário, ou "Deus só cria por um direito legítimo (verdadeiro, bi-l-haqq), e isso significa que concede à criação sua exata medida, aquilo que é verdadeiramente exigido por ela" ${ }^{30}$. Afirmar que a mulher é inferior ao homem com base nestes argumentos é o mesmo que comparar os Nomes do Real, como afirmar que o Poderoso supera sobre o Amoroso, ou negar a singularidade específica a cada criatura pois, de acordo com Ibn 'Arabī, as realidades não podem ser comparadas:

Não existe comparação válida entre os nomes Divinos por dois moti-

27 Futūhāt, III 454.1: The Sufi Path of Knowledge, p. 119.

28 Futūhät, III, 90.18,28: Sufi Path of Knowledge, p. 141.

29 Como, por exemplo, a menstruação ainda é vista como uma impureza e a mulher impedida de orar em função de sua impureza, quando o $\breve{S} a y h$ afirma que a oração não é compulsória nesse período pelo acolhimento divino dos significados existentes nesse processo e, em outras passagens enfatiza a misericórdia divina para com a mulher nesse período.

30 Futūhāt, cap. 73, questão 28: Eric Winkel, Questions, p. 96. 
vos: primeiro é que a relação dos nomes à Substância é uma relação única (nisbat wāhidat), assim não há comparação possível. Se houvesse uma superioridade de alguns planos em relação a outros, a partir do que é dependente e condicionado às verdades divinas, ocorreria igualmente uma comparação entre os nomes Divinos. Alguns seriam mais excelentes que outros e não há quem afirme isso, seja intelectualmente ou com base na Revelação. A universalidade de um nome não prova sua excelência pois a excelência ocorre naquilo que é receptivo ao seu brilho e, portanto, a dificuldade em ser receptivo não pertence ao nome; ou, ainda, a excelência ocorre no que lhe é passível de ser descrito, sem a qual não é descrito.

A segunda perspectiva é que os nomes Divinos se referem à Sua dāt e a dāt é única, enquanto a comparação exige multiplicidade e a coisa não pode ser mais excelente que ela mesma e, portanto, a comparação não é válida... Ela (a essência) está em correlação à isto ou aquilo enquanto criadora e é na criação disso ou daquilo a rainha e, na correlação disso ou daquilo, a mulher sábia, onde quer que correlaciones as nobres qualidades, pois a 'ayn é wāhda, una. ${ }^{31}$

O Šayh continua o assunto afirmando que entre as criaturas também não pode haver comparação pois estas estão associadas aos níveis da manifestação dos nomes Divinos e, ainda que os nomes Divinos possuam êxtase ou prazer em sua substância e em sua perfeição, seu gozo naquilo em que emergem visivelmente é um gozo pleno em função da manifestação de seu domínio e este gozo é o que significa o pronome "você" (ou laysa illā bi-kum). Isto significa que cada singularidade (cada criatura) já é um "grau" do ser, enquanto uma "distinção" ou diferenciação de wuǧũd e não enquanto uma hierarquia de superioridade ou inferioridade pois estas noções implicam em correlação e, diante da unicidade ou do ser único, não há divisão ou antagonismo, mas sinergia.

Há aqui, portanto, a indicação do que significa o "grau a mais": cada criatura, através da plenitude da singularidade que a entifica, tem acesso a insān al-kāmil, o ser humano completo. A singularidade é potencialmente o "objeto global" no qual o Real se espelha, a realidade adâmica. Ela só se abre na medida em que o indivíduo, seja masculino ou feminino, tornar-se receptivo à Presença divina que em si mesma é completa. A excelência deve-se, portanto, à inclusividade e abrangência pois, segundo o $\breve{S}$ ay h , algo que pode ser classificado como inferior pode ser igualmente classificado como superior em relação a algum outro atributo e, deste modo, a comparação é apenas quanto aos estados e estações que conduzem à plenitude.

31 Futūhāt, cap. 73, questão 29: Questions, p. 97. 


\section{REGEPTIVIDADE COMO DINÂMICA DE PLENITUDE}

A receptividade à plenitude pode ser entendida a partir da relação do encontro necessário que implica na condição de ser: o encontrar-ser-encontrado possui duas faces que devem se contemplar simultaneamente e o encontro se dá pela transitividade da identidade entre ambos. Isto significa que deve haver um movimento atrativo que impulsione o encontro e este movimento é o que Ibn "Arabī denomina de "vida": "A ordem universal é perplexidade e a perplexidade é agitação e movimento, e o movimento é vida"32. A vida necessariamente aproxima cada criatura daquilo que ela é, mas isso exige o preparo ou a disposição de cada um em se contemplar frente a frente. A receptividade, portanto, longe de ser uma característica passiva, exige a atividade da recepção, a disposição ou a capacidade do acolhimento, a "prostração do coração" (suğŭd), ou seja, a reverência e inclinação, a interiorização capaz de buscar a raiz de si mesmo. E isto significa um esforço contínuo, onde ambos, homens e mulheres se distraem facilmente. Escreve Ibn 'Arabī:

Aquele que reconhece sua raiz reconhece sua 'ayn, isto é a si mesmo, e quem reconhece a si mesmo reconhece seu Amado e aqueles que reconhecem a si mesmos não levantam suas cabeças; mas ainda assim levantariam suas cabeças pois foram criados 'segundo a forma' de seu Senhor e uma das qualidades de seu Senhor é a Elevação e certamente levantariam suas cabeças! Mas após essa elevação lhes é dito: inclinem-se! E tu abaixas tua cabeça, teu coração se inclina e ergues a cabeça (do estado) de prostração (suğüd): mas isso não é permanente, pois a qibla à qual te inclinas não permanece perpetuamente e a direção na qual te inclinastes não permanece perpetuamente. Tu te elevas em função do lugar de suğúd. O coração se inclina e não se levanta pois inclina-se a seu Senhor. Sua qibla é seu Senhor e seu Senhor permanece sempre. ${ }^{33}$

A interiorização, o prestar atenção à presença essencial depende do contínuo alinhamento com a realidade pois as formas que a Presença assume se renovam a cada instante: a consciência se eleva, mas o coração necessariamente permanece inclinado, em receptividade e

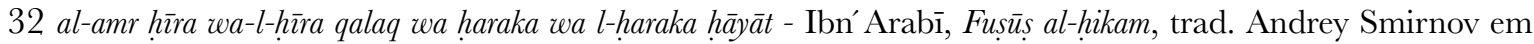
Il Vortice Divino. Il Monismo come Interdipendenza tra zähir-bātin: il punto di vista Musulmano e la Fïlosofia Mistica di Ibn Arabī. - Veja-se também Fusūs al-hikam (The Ringstones of Wisdom), trad. Caner Dagli, p. 256. A palavra vórtice, hìra, também aparece como hayra, perplexidade.

33 Futūhāt, cap. 73, questão 101: Questions, p. 255. 
abertura. Assim, o próprio movimento da vida exige tanto a receptividade quanto a atividade, o acolhimento e a expressão da forma necessária num determinado instante.

A ascensão da consciência revela os diversos nomes constituintes da Identidade essencial de cada criatura e estes nomes possuem tanto a expressão da Majestade quanto da Beleza, pela própria paridade que constitui a correlação da ordem universal. Assim, a expressão do gênero, aspecto mais externo de cada um e que se apresenta como um "sinal" distintivo da realidade, só é plenamente compreendido pelo "atravessamento" de wuğūud: a cada instante, em função da rotação da presença dos nomes e da reciprocidade da Presença essencial às necessidades do mundo, há uma transitividade masculino-feminino, feminino-masculino, que se se apresenta em diversos "graus" de masculinidade e feminilidade, de tal modo que ninguém é absolutamente homem nem absolutamente mulher. Com essa afirmação não estamos questionando as opções sexuais de cada um, pertencentes à correlação entre sua biologia e sua vivência de si e que se expressa em seus relacionamentos, pois seus relacionamentos já respondem, antes mesmo de sua biologia, à característica da Identidade essencial dada pela Presença dos Nomes, por um lado, e à disponibilidade da consciência pessoal, ou do local individual em acolher essas presenças. Para Ibn 'Arabī, todo o visível, não importa em qual plano se manifeste, é um sinal que indica uma realidade. $\mathrm{O}$ sentido desse sinal, ou seus significados, mudam conforme as relações dos encontros nele estabelecidos. Assim, tanto os corpos quanto as realidades que os vivificam devem ser "lidos" de acordo com a Presença que portam e, para compreender os significados, temos de "atravessar" os sinais e não tomálos como absolutos. A forma humana não é excessão, nem tão pouco o gênero.

Isso nos leva ainda a uma última questão: grande parte dos conceitos associados ao gênero que vivenciamos ainda hoje decorrem de processos culturais e históricos complexos em si mesmos. Mas, considerando o que nos ensina o $\breve{S} a y h$, podemos cortar caminho por um atalho muito simples: a maior parte das criaturas que se apresentam com a forma "humana" ainda não é humana. Como a forma humana plena é estabelecida a partir da forma divina - correspondente à Presença do Senhor qualificado pelos nomes que entificam o indivíduo - só adquire plenitude quanto "unifica" todos os planos da Identidade, ou seja, o físico, o intermediário e o espiritual com sua realidade mais profunda, a Identidade essencial, a "raiz" do Senhor. Isto significa que é necessário atualizar os atributos essenciais ou os "nobre traços de caráter", a Presença essencial dos nomes que constituem cada identidade. Como as criaturas estão identificadas com apenas uma parte de si mesmas, normalmente seu aspecto físico imediato, permanecem na condição de al-insān al-hayawān, o humano-animal, o estado pré-atualização de si mesmo, de modo que há uma trajetória de ascensão ou integração de si que deve ocorrer.

Segundo o $\breve{S} a y h$, o ser humano é a síntese do cosmos e congrega em si todos os reinos, desde o mineral, o vegetal, o animal, o humano e o divino. $\mathrm{O}$ corpo físico é preparado, no ventre materno, a partir das substâncias minerais e vegetais que o compõem e, a princípio, cor- 
responde apenas a um corpo animal. Quando o espírito se une a esta forma, faz dela uma forma humana; cada corpo é, portanto, um suporte adequado para uma singularidade que é eminentemente espiritual e, entre eles (corpo e espírito) há o mesmo nível de correlação da Presença essencial: “qualquer que seja a forma concedida pelo 'Formador' é idêntica a esse, pois não há nada além dele... Adão consiste num indivíduo no qual o cosmos é unificado... e surgiu segundo a forma do nome Allāh, pois este nome compreende todos os Nomes divinos". 34

O humano-animal é o substrato adâmico exterior, enquanto al-insān al-kāmil corresponde ao interior que se estabelece como análogo à Presença divina. A racionalidade, considerada o atributo que distingue o humano dos animais, não é aceita por Ibn 'Arabī como um atributo exclusivamente humano. Para ele todos os seres vivos, não importa como sejam categorizados, são "racionais" pois toda expressão viva significa uma expressão simultaneamente ontológica e epistemológica da realidade ${ }^{35}$ : o Vivo se reconhece como vivo em todos os seres, animados ou inanimados e, portanto, é cognoscente e segue sua orientação essencial:

A expressão racional permeia todo o cosmos. Não é uma característica exclusiva do homem, conforme imaginam aqueles que fazem da racionalidade sua diferenciação. $\mathrm{O}$ desvelamento mostra que o humano não possui, exclusivamente, esta definição. O humano é definido pela Forma Divina. Aquele que não possui esta definição não é humano. Ao contrário, é um animal cuja forma se assemelha à aparência humana exterior. ${ }^{36}$

Ibn 'Arabī afirma que as formas corporais (sejam físicas ou sutis, como as do mundo intermediário), enquanto receptoras de um sentido ou significado, são figuradas a partir da luz, do fogo, do pó, de acordo com as raízes de suas configurações e de sua Identidade essencial, por um processo de correspondência e inter-relação, seguindo o mesmo processo transitivo huwa/hiya através do vínculo do terceiro, a força atrativa da identidade (singularidade). Nesse sentido, o corpo não possui uma conotação negativa, ao contrário, seus elementos são vivos e respondem igualmente pela presença da realidade. São, em relação à Identidade essencial, o que esta é em relação ao desvelamento do Real: local de manifestação.

No entanto, estes locais possuem o preparo adequado, uma receptividade própria a uma determinada imagem do Real e são, portanto, locais viventes e "inteligentes", capazes de te-

34 Futūhāt, II, 123.35: The Sufi Path of Knowledge, p. 276.

35 Veja-se Chittick, The Self Disclosure of God, p. 285.

36 Futūhāt, III, 154.18: The Sufi Path of Knowledge, p. 276. 
stemunhar a realidade, de modo que não há forma, nem mesmo mineral, sem que uma alma a habite. O Šayh lembra do versículo corânico 24:24: "Dia virá em que suas línguas, suas mãos e seus pés testemunharão contra eles, pelo que tiverem cometido". As partes corporais não depõem contra si mesmas, o que seria uma "confissão", mas sim como "testemunhas" da Identidade (da Presença do Senhor) nelas presente. "Isto prova", escreve Ibn 'Arabī, "que as partes corporais são interligadas com a alma racional, tanto quanto as propriedades são interligadas com seu possuidor e assim é o caso da raiz e a raiz é o Real"37.

No caso do ser humano, no entanto, como na raiz de sua Identidade estão potencialmente todos os nomes da realidade, sua forma está em analogia com a Forma divina e a singularidade que a permeia necessariamente deve estar em correspondência com sua "qibla", sua Presença essencial. O corpo físico é, para esta Presença, o plano da terra, enquanto os demais corpos (de Eva, de Jesus e o Adâmico) estão em correspondência com os demais planos de wuğūd. Para que a Presença ou a Identidade essencial se "realize" como um local da realidade, estes planos devem estar correlacionados, alinhados, funcionando como uma unicidade, "submissos" a seu Senhor. Submisso, na linguagem do Šayh, é o mesmo que a condição de "servo" do Real, o coração receptivo, ou o cristal lapidado que irradia o brilho da presença.

\section{ATUALIZAÇÃO E GULTURA}

Tanto quanto o ser humano não atualize sua forma real, sua cultura também permanece sem atualização sendo, portanto, comparável à expressão cultural de qualquer outro animal racional: todas as espécies produzem modos de interação consigo mesmas e com o mundo ao redor de acordo com as necessidades e especificidades de sua constituição. Isto implica que a cultura humana também só se atualiza quando se estabelece como interação de reciprocidade entre os diversos planos da realidade, reciprocidade esta que reflete a interação necessária entre os atributos do Real.

Assim, podemos entender que, se a grande maioria dos seres humanos não atualiza sua identidade essencial, suas sociedades refletem este estado. Segundo o Šayh, muitas das recomendações que o Alcorão faz em relação à vida cotidiana e que se tornaram parte do corpo da $\breve{S}{ }^{-} \bar{c} a$ - entendida aqui como Lei Islâmica - surgiram em função disso, como por exemplo, o versículo sobre o hiğāa:

Tu não vês que o verso do hiğăa não desceu a partir do princípio? Não, desceu porque um dos seres criados clamou por ele. Este ver- 
so e outros. E muitos dos que se tornaram Lei foram enviados por razões mundanas; se não fosse por isso, Deus não os teria feito descer. Em função disso o Povo de Deus diferencia entre a ordem Divina que vem do princípio (da raiz) e aquela que surge depois, como uma exigência da parte das criaturas, de tal modo que esta exigência se tornou o motivo do descenso daquela ordem. É como se o Real fosse requisitado e obrigado a fazê-lo descer, do contrário não o faria. E isto é diferente de quando a ordem desce a partir do princípio. ${ }^{38}$

Eric Winkel ${ }^{39}$, em sua tradução deste texto explica, segundo relato de Â''š̌a, esposa mais nova do Profeta Muhammad, que o versículo desceu (em revelação) depois de um episódio em que 'Umar ibn al-Hatțāb, aconselha o Profeta a cobrir suas esposas com véus, conselho que esse teria se negado a seguir. O problema estaria em torno a Sauda binti Zama'at, uma de suas esposas que, sendo uma mulher grande, teria saído à noite, para cumprir necessidades fisiológicas, e teria sido vista por 'Umar. Em outras palavras, ainda que 'Umar estivesse na mesquita, teve a oportunidade de "espiar" Sauda em uma situação embaraçosa de urgência íntima.

Ibn 'Arabī escreve, um pouco antes deste relato, que a mulher, em sua formação, respondeu ao chamado divino em seu estado de vazio ou através da vacuidade de sua 'ayn, sem restrições, humilde diante da majestade de seu Objeto de visão, sem usar nem reconhecer velamento algum, hiğăb algum. No entanto, quando a natureza distinguiu os diferentes planos do ser, surgiu no animal, e em especial no animal-humano, uma vigilância protetora - ǵayrat - ou "ciúme". E é em função disso, escreve o Šayh que o Real "criou o intelecto no ser humano, para repelir o domínio excessivo do apetite e do ego, ambos consequências da característica do ciúme" ${ }^{\prime 40}$.

Um pouco adiante, nesse mesmo relato, Ibn 'Arabī afirma que as "mulheres são šaqā $r q$ dos homens", (luzes ou raios luminosos, palavra que também é traduzida por "semelhante") e que isto é um remédio para a cura deste ciúme. No entanto, diz ele, frequentemente este tipo de ciúme é interpretado como virtude: 'Umar, por um lado, em seu zêlo religioso e necessidade de proteger a família do Profeta Muhammad, pede a este que vele suas esposas. Por outro, se estivesse realmente orientado em direção à qibla (pois estava orando na mesquita), não teria observado Sauda que, para cumprir com uma necessidade física, espera a noite, ou seja, já estava, no melhor de suas habilidades, sob um hiğăăb.

38 Futūhāt, capítulo 72, 16. hadīt: Eric Winkel, The Count, p. 45. Na sequência, Ibn 'Arabī aconselha a aceitar estas recomendações divinas com tranquilidade, pois as regras divinas são suaves para aqueles que as acolhem com coração aberto.

39 Idem, p. 45, nota 57.

40 Futūhāt, capítulo 72, 16. hadīt,: The Count, p. 41. 
O homem-animal se confunde, muitas vezes, com aquele que busca perfeição. E o Šayh afirma: "Com que frequência isso acontece! Quanto tenho sofrido com esse assunto, por causa das pessoas veladas que têm sua inteligência dominada por seus egos. Eu tento segurá-los por seus cintos, para preveni-los de cairem no Fogo, mas eles se atiram nele mesmo assim" ${ }^{41}$.

E, de certo modo, isso ainda nos acompanha: a condição feminina hoje continua como uma decorrência de uma sociedade humana que permanece no estado do humano-animal: quer seja nas sociedades tribais, tradicionais ou ocidentais, a mulher ainda não adquiriu, em sua grande maioria, nem mesmo o status de "pessoa". Como escreve Ibn 'Arabī, quando o homem se aproxima da mulher a partir de sua condição de al-insān al-ḥayawān, está distante de sua fonte essencial e desconectado de si mesmo:

Para ele, o ato conjugal permanece uma forma sem espírito: e ainda que aquela forma possua um espírito, não é testemunhado por aquele que se aproxima de sua esposa ou de qualquer outra mulher estritamente pelo prazer, mas sem conhecer o "quem". Permanece ignorante de sua própria alma tanto quanto os outros o ignoram até que ele se apresente de modo a ser conhecido... tal pessoa ama adquirir prazer e, portanto, ama o local onde o prazer se encontra, ou seja, a mulher. No entanto, o espírito da questão permanece oculto para ele. Se ele o conhecesse saberia em quem encontra prazer e quem encontra prazer. Então seria perfeito ${ }^{42}$.

Podemos dizer, no entanto, que, considerando-se tanto homens quanto mulheres como pertencentes igualmente à "categoria" de humano-animal, o texto aplica-se a ambos. Enquanto o animal segue seus instintos por sua "racionalidade", por aquilo que lhe faz receptivo à vida, o mesmo impulso no ser humano implica no distanciamento do Real pois a forma verdadeiramente humana corresponde àquela onde o encontro de wuǧŭd consigo mesmo é o "êxtase", o gozo que move o Alento divino. Em outras palavras, o distanciamento do Real estabelece não só absolutos em si mesmos quanto impede a transitividade ou a comunicabilidade da realidade como fluxo e influxo de Presença. A proximidade, por outro lado, é "perplexidade", "vida".

É nesse sentido, por exemplo, que o Šayh escreve, no último capítulo do Fușuss, sobre o Profeta Muhammad: "Sua realidade foi marcada pela singularidade primordial e seu aparecimento pela triplicidade, e em função disso ele falou - em relação ao amor, a origem de todo existente: 'Três coisas fizeram-se amadas por mim nesse mundo', por causa da triplicidade nele

41 Idem, p. 47.

42 Citado por Sachiko Murata, The Tao of Islam: Gender Relationship in Islamic Thought, p. 195. Texto original do Fusūs al-hikam, The Bezels of Wisdom, p. 276, tradução de Austin. 
inerente. A seguir mencionou a mulher e o perfume, e completou dizendo que na oração encontrou consolo" 43 .

O "grau acima" que caracteriza al-insān al-kāmil necessita da transitividade da Identidade entre os correlatos, transitividade essa que se expressa como amor e vida, do contrário temos dois absolutos justapostos que se excluem mutuamente. O ponto central na doutrina de Ibn 'Arabī, marcada aparente e exatamente pela ambivalência huwa/la-huwa, ele-não-ele, é o terceiro incluso: o movimento de traduzibilidade entre estes, que os unifica sem descaracterizá-los, o amor em potencial.

E este estado de traduzibilidade faz do capítulo de Muhammad, no Fușuss, uma alternância da condição humana onde masculino e feminino oscilam entre interior e exterior, superior e inferior, como o Alento do Todo Misericordioso, inspiração e expiração, que se traduz na metáfora do perfume: o masculino encontra sua plenitude no feminino e o feminino encontra sua plenitude no masculino não por uma questão imediata de gênero, mas pela confluência do desvelamento divino, ainda que o gênero seja um sinal indicando esta Presença. Em outras palavras, masculino e feminino não são conceituados a partir de si mesmos, pois em si, como absolutos, não existem. Nem tão pouco existem no confronto dialético dos opostos, mutuamente excludentes, onde nem se reduzem um ao outro nem se amorfizam num andrógino. Masculino e feminino convergem um ao outro, ocorrem enquanto fluxo de vida e identidade, assim como os nomes da Majestade necessariamente confluem para os da Beleza e vice-versa. A confluência é necessariamente gozo ${ }^{44}$ e como tal, os opostos não são contrários, nem se complementam, nem se fundem: se incluem, se traduzem.

43 Fusūs al-hikam ( The Bezels of Wisdom), trad. Austin, p. 272.

44 Veja-se The Sufi Path of Knowledge, p. 212: "Wuğüd significa encontrar (wiğgan) o Real em êxtase (wağd)" - Futūhāat, II,538.1 